\title{
Surgeon Attitudes Toward Physiotherapeutic Scoliosis- Specific Exercises in Adult Patients With Spinal Deformities
}

\author{
LEAH STEINMETZ, BS, ${ }^{1}$ FRANK SEGRETO, BS, ${ }^{1}$ CHRISTOPHER VARLOTTA, BD,${ }^{1}$ \\ KELLY GRIMES, DPT, ${ }^{2}$ PRACHI BAKARANIA, DPT, ${ }^{2}$ HAGIT BERDISHEVSKY, FPT, ${ }^{2}$ \\ TOMI LANRE-AMOS, MD, ${ }^{1}$ CHARLA R. FISCHER, MD ${ }^{1}$ \\ ${ }^{I}$ New York University Langone Orthopedic Hospital, New York, New York, ${ }^{2}$ Spine/Scoliosis Service, Columbia University, New York, New York
}

\begin{abstract}
Background: Physiotherapeutic scoliosis-specific exercise (PSSE) has proven to be an important treatment for patients with adolescent idiopathic scoliosis. However, there is a lack of understanding of the role of PSSE in older adults with spinal deformity.

Methods: An electronic, 14-question survey with questions regarding the use of physical therapy (PT) and PSSE for adult spinal deformity was administered to all Scoliosis Research Society members. Physician location, age, specialty, years in experience, and management preferences were quantified using descriptive analyses.

Results: Of the 98 surgeons who participated in this study, the majority of respondents were from North America $(71.1 \%)$, and the mean age was $51.87 \pm 10.93$ years; approximately $98 \%$ of respondents were orthopedic surgeons, and $48.0 \%$ had been in practice for more than 21 years. Sixty-four percent reported they prescribed PT in their practice, with $52 \%$ of respondents often using PT as nonoperative treatment; $21.4 \%$, preoperative; and $40.8 \%$ postoperative. The primary reason for PT referral was persistent pain $(40.3 \%)$, followed by impairments to the patient's balance or gait $(34.3 \%)$ and difficulty with daily living activities $(25.4 \%)$. The primary indications for not referring postoperative patients to PT were lack of perceived value from PT (50\%), lack of evidence supporting the benefits from PT (31.3\%), and a lack of physical therapists appropriately trained for scoliosis $(18.8 \%)$. Of the respondents, $74 \%$ were familiar with PSSE and $66 \%$ were comfortable prescribing PSSE postoperatively. In addition, $28 \%$ of respondents agreed that $>12$ weeks postoperation was the ideal time for PSSE referral, followed by 6 to 8 weeks postoperation $(26.2 \%)$ and immediately postoperation (18\%).

Conclusions: The results show that the majority of respondents prescribed PSSE solely for nonoperative treatment. Respondents who did not prescribe PSSE reported skepticism due to a lack of perceived value. This suggests the need for further research into the benefits of PSSE.

Level of Evidence: 5 .

Clinical Relevance: Physiotherapeutic Scoliosis Specific Exercises (PSSE) is an important non-operative treatment for patients with Adolescent Idiopathic Scoliosis (AIS) but is understudied in Adult Spinal Deformity (ASD) patients, suggesting further clinical research. This study demonstrates that only two-thirds of the respondents familiar with PSSE were comfortable prescribing PSSE postoperatively suggesting the need for further research into the effectiveness and benefits of PSSE in ASD patients.
\end{abstract}

Other \& Special Categories

Keywords: Schroth, physiotherapeutic scoliosis specific exercises, adult deformity

\section{INTRODUCTION}

Scoliosis in adulthood may present itself as a continuation of adolescent idiopathic scoliosis (AIS), or it may develop as a result of age-related degenerative conditions. ${ }^{1}$ The prevalence of adult spinal deformity (ASD) has been reported to be between $32 \%$ and $68 \%{ }^{2}$

Individuals with ASD present with a variety of symptoms, including pain, postural asymmetry, balance dysfunction, diminished endurance, and selfimage issues, as well as diminished quality of life. ${ }^{1}$ As the activity level and age of patients with scoliosis continues to increase, there has been a growing need for nonoperative treatment to circumvent risks of undergoing a major operation at an older age.

Evidence for the value of nonoperative intervention in this population is limited. We can draw from a growing evidence base in the AIS population, which is seeing increased support for the role of bracing and physiotherapeutic scoliosis-specific exercises (PSSE) as the mainstays of nonoperative care for this patient population. ${ }^{3,4}$ The publication of the Bracing in Adolescent Idiopathic Scoliosis Trial (BrAIST) study 
demonstrated the efficacy of bracing for AIS on the basis of clearly defined clinical parameters. ${ }^{3}$ Physiotherapeutic scoliosis-specific exercises are a group of approaches that consider detailed assessment of scoliotic curve patterns and involve postural correction and incorporation into daily function. ${ }^{5,6}$ This strategy uses various exercises, depending on the approach, that train a partnership between activation and strengthening of the deep stabilizing muscles of the spine and the core, in partnership with breathing strategies to guide the patient to a more centered alignment, then train endurance to maintain it in daily function. ${ }^{7}$ There are a number of different approaches that exist under the umbrella of PSSE. The most widely researched are Schroth and the scientific exercise approach to scoliosis. Physiotherapists trained to assess and manage individuals with spine deformity receive extensive postgraduate training that includes understanding scoliosis pathomechanics, progression, and thorough clinical and radiological assessment and management strategies based on each individual's 3-dimensional alignment rather than 2-dimensional alignment measurements such as pelvic tilt. In the United States, for example, the training process most widely available is Schroth training through the Barcelona Scoliosis Physical Therapy School. The basic level of training is 65 hours over 10 days, well beyond the minimal amount of scoliosis education provided at an entry-level physical therapy education program in the United States. ${ }^{8}$ Recent literature has provided evidence that PSSE prevents curve progression, minimizes respiratory dysfunction, prevents spinal pain syndromes, and improves aesthetics via postural correction in the adolescent population. ${ }^{1,6,9-15}$ PSSE has also been shown to enhance the effectiveness of bracing, demonstrating superiority over bracing alone in affecting Cobb angle magnitude, trunk rotation, and quality-of-life scores in the AIS population. ${ }^{16}$

In adults with idiopathic scoliosis persistent since adolescence and/or de novo or degenerative scoliosis, there is a lack of data on the effectiveness of physical therapy (PT) and PSSE, suggesting the need for further clinical research. In adults with spine deformity, PSSE typically requires a more advanced level of training or certification (45 additional hours beyond a basic level of scoliosis education) on the part of the therapist and the completion of a clinical exam verifying competency in assessment and intervention skills to be safe and appropriate. In addition, the clinical application of PSSE for this patient popula- tion, including being managed postoperatively, requires a deep understanding of the aging spine, the impact of 3-dimensional alignment changes, particularly sagittal changes, on quality of life in this population, and clinical implications of ASD surgical intervention. PSSE goals in adults are to improve pain and quality of life, slow or halt curve progression, and optimize 3-dimensional alignment in the nonoperative, preoperative, and postoperative phases of management. Existing evidence that supports PSSE in adults with spine deformity is largely limited to case reports and case series; however, the recent publication of a randomized controlled trial demonstrating effectiveness of PSSE for adult idiopathic scoliosis (AIS persistent to adulthood) indicates that PSSE may be a viable intervention option for this population. This particular study demonstrated improved disability as measured by the Oswestry Disability Index as well as improved Cobb angle measurement in the group treated with PSSE as compared with the group receiving general physiotherapy. ${ }^{5}$ Evidence for PSSE as distinct from traditional physical therapy in the perioperative phase (prehabilitation and postoperative care) of ASD management does not exist.

There is a need for future research in the outcomes of PSSE preoperation and postoperation to determine the effectiveness of PSSE treatment in older adults. To better direct additional research on PSSE, there must be an improved understanding of physician opinions toward PSSE in this population. Therefore, the aim of this study is to understand surgeons' attitudes toward PSSE as a plausible treatment option compared with traditional low back physical therapy in older adults with ASD.

\section{METHODS}

This is a prospective survey study of the adult and pediatric spine surgeon members of the Scoliosis Research Society. An electronic, 14-question survey was administered online to 785 society members with questions regarding the use of PT and PSSE for ASD. The survey was designed and administered using SurveyMonkey. Participants were recruited through email. No incentives were provided for participation. The survey, in Table 1, evaluated for referral patterns around PT and PSSE in the ASD population. The physicians were asked to respond to questions on the basis of country of residence, age, specialty, years in experience, and management preferences. The respondents were asked whether they were comfortable recommending PT nonoperatively, preoperatively, or 
Table 1. Survey questions and responses.

\begin{tabular}{|c|c|c|}
\hline Question & Response & n $(\%)$ \\
\hline \multirow[t]{6}{*}{ Region } & North America & $69(71.1)$ \\
\hline & Europe & $11(11.3)$ \\
\hline & Asia & $8(8.2)$ \\
\hline & South America & $7(7.2)$ \\
\hline & Australia & $1(1)$ \\
\hline & Middle East & $1(1)$ \\
\hline \multirow[t]{2}{*}{ Please describe your training: } & Orthopedic spine & $94(97.9)$ \\
\hline & Neurosurgery spine & $2(2.1)$ \\
\hline \multirow{3}{*}{ Did you do a fellowship in the following (mark all that apply): } & Orthopedic spine surgery & $52(53.1)$ \\
\hline & Pediatric orthopedic surgery & $54(55.1)$ \\
\hline & Combined ortho-neuro spine surgery & $3(3.1)$ \\
\hline \multirow[t]{3}{*}{ How many years have you been in practice? } & $0-10$ years & $25(25.5)$ \\
\hline & $11-20$ years & $26(26.5)$ \\
\hline & $>21$ years & $47(48)$ \\
\hline \multirow{2}{*}{ Do you treat adult spinal deformity in your practice? } & Yes & $52(53.1)$ \\
\hline & No & $46(46.9)$ \\
\hline \multirow{2}{*}{$\begin{array}{l}\text { Do you utilize the services of physical therapy for your patients with adult } \\
\text { spinal deformity? }\end{array}$} & Yes & $49(63.6)$ \\
\hline & No & $28(36.4)$ \\
\hline \multirow{3}{*}{$\begin{array}{l}\text { If yes, when do you refer for adult spinal deformity patients to physical } \\
\text { therapy? (check all that apply) }\end{array}$} & Nonoperative management & $51(52)$ \\
\hline & Presurgical optimization & $21(21.4)$ \\
\hline & After surgery & $40(40.8)$ \\
\hline \multirow{5}{*}{$\begin{array}{l}\text { If you indicated that you refer patients to physical therapy after scoliosis } \\
\text { fusion surgery, what percentage of your patients do you refer? }\end{array}$} & $0 \%-20 \%$ & $26(40)$ \\
\hline & $21 \%-40 \%$ & $5(7.7)$ \\
\hline & $41 \%-60 \%$ & $6(9.2)$ \\
\hline & $61 \%-80 \%$ & $7(10.8)$ \\
\hline & $81 \%-100 \%$ & $21(32.3)$ \\
\hline \multirow[t]{3}{*}{ If you refer patients for physical therapy, what are the reasons for referral? } & Persistent pain & $27(40.3)$ \\
\hline & Impaired balance/gait & $23(34.3)$ \\
\hline & Difficulty with ADLs & $17(25.4)$ \\
\hline \multirow[t]{3}{*}{$\begin{array}{l}\text { If you do not refer patients after scoliosis fusion surgery to physical } \\
\text { therapy, what are the reasons you do not refer? }\end{array}$} & $\begin{array}{l}\text { Lack of evidence for the role of } \\
\text { physical therapy }\end{array}$ & $15(31.3)$ \\
\hline & $\begin{array}{l}\text { Lack of perceived value for the role } \\
\text { of physical therapy }\end{array}$ & $24(50)$ \\
\hline & $\begin{array}{l}\text { Lack of access to physical therapists } \\
\text { with appropriate knowledge of } \\
\text { scoliosis and surgical procedure/ } \\
\text { precautions }\end{array}$ & $9(18.8)$ \\
\hline \multirow{2}{*}{$\begin{array}{l}\text { Are you familiar with physiotherapeutic scoliosis-specific exercise (PSSE) } \\
\text { such as Schroth physical therapy for scoliosis? }\end{array}$} & Yes & $67(73.6)$ \\
\hline & No & $24(26.4)$ \\
\hline \multirow{2}{*}{$\begin{array}{l}\text { If you are familiar with PSSE such as Schroth physical therapy for scoliosis } \\
\text { and have a local provider, would you feel comfortable to refer to their } \\
\text { care after the fusion to work on impaired respiratory function, difficulty } \\
\text { with ADLs, impaired balance and gait, and any pain? }\end{array}$} & Yes & $50(65.8)$ \\
\hline & No & $26(34.2)$ \\
\hline \multirow[t]{5}{*}{ What time frame after surgery is ideal to refer to PSSE? } & Immediately post-op & $11(18)$ \\
\hline & 3-4 weeks post-op & $9(14.8)$ \\
\hline & 6-8 weeks post-op & $16(26.2)$ \\
\hline & $8-12$ weeks post-op & $8(13.1)$ \\
\hline & $>12$ weeks post-op & $17(27.9)$ \\
\hline
\end{tabular}

Abbreviations: ADLs, activities of daily living; post-op, postoperative.

postoperatively; they were also asked whether they did not recommend PT and, if so, why not. Specific questions about perspectives on PSSE and optimal treatment times to initiate PT following surgery were also asked. Descriptive statistical analysis was performed using SPSS software (version 23.0, IBM Corp, Armonk, NY).

\section{RESULTS}

\section{Surgeon Demographics}

A total of 98 surgeons responded to the survey request. The majority of the respondents were orthopedic surgeons $(97.9 \%)$ and the rest were neurosurgeons $(2.1 \%)$, with a mean age of $51.87 \pm 10.93$ years. Of the respondents, $53 \%$ had been trained in an orthopedic spine fellowship; $55.1 \%$, pediatric orthopedic fellowship; and $3.1 \%$, combined ortho-neuro surgery fellowship. The majority of respondents were from the United States $(66.3 \%)$; others from Canada $(4.1 \%)$, Brazil $(4.1 \%)$, and Australia (3.1\%). Stratified by region, the majority of respondents were from North America $(71.1 \%)$, followed by Europe $(11.3 \%)$, Asia (8.2\%), South America (7.2\%), and the Middle East (1\%). A majority of respondents had 
Table 2. Characteristics of surgeons prescribing physical therapy for patients with adult spinal deformity.

\begin{tabular}{lrrr}
\hline & No & Yes & $\boldsymbol{P}$ Value \\
\hline Region & & & .052 \\
$\quad$ North America & 23 & 54 & \\
$\quad$ Europe & 2 & 8 & \\
Asia & 1 & 2 & \\
South America & 0 & 0 & \\
$\quad$ Australia & 1 & 1 & \\
$\quad$ Middle East & 0 & 1 & \\
Years in training & & & .389 \\
0 to 10 & 7 & 17 & \\
11 to 20 & 9 & 20 & \\
21 or more & 12 & 30 & \\
Specialty & & & .533 \\
$\quad$ Orthopedic spine surgeon & 27 & 46 & \\
$\quad$ Neurosurgical spine surgeon & 0 & 2 & \\
Fellowship & & & \\
$\quad$ Pediatric & 25 & 10 & .000 \\
$\quad$ Orthopedic spine & 4 & 43 & .000 \\
$\quad$ Ortho-neuro combined & 0 & 3 & .297 \\
\hline
\end{tabular}

more than 11 years of clinical experience, which was measured by the number of years in practice: $25.5 \%$ of respondents had been practicing for 0 to 10 years, $26.5 \%$ for 11 to 20 years, and $48.0 \%$ for more than 21 years. These results are summarized in Table 2.

\section{Practice of PT Referral for Patients With Spine Deformity}

Surgeon practice patterns showed that $53.1 \%$ of respondents treat ASD in their practice. Of the total data set, 64\% reported prescribing PT in their practices, with $52 \%$ of respondents often using PT as nonoperative treatment; $21.4 \%$, preoperative; and $40.8 \%$, postoperative. Of the surgeons who treat spine deformity in clinical practice, $90 \%$ reported prescribing PT in their practices, with $86 \%$ of respondents using PT for nonoperative management, $40 \%$ in the prehabilitation phase, and $73 \%$ postoperatively.

\section{Practice of PT Referral for Patients With Spine Deformity After Surgery}

Of those who indicated referral to PT after spinal deformity surgery, $40 \%$ of respondents reported prescribing PT for $0 \%$ to $20 \%$ of their patients, whereas $32.3 \%$ reported prescribing $\mathrm{PT}$ for $81 \%$ to $100 \%$ of their patients. The primary reason for PT referral was persistent pain $(40.3 \%)$, followed by impairments to the patient balance or gait $(34.3 \%)$ and difficulty with daily living activities $(25.4 \%)$. The primary indications for not referring postoperative patients to PT were lack of perceived value from PT $(50 \%)$, lack of evidence supporting the benefits from PT $(31.3 \%)$, and a lack of physical therapists appropriately trained for scoliosis $(18.8 \%)$.

\section{Practice of PSSE Referral for Patients With Spinal Deformity}

Of the respondents, $74 \%$ were familiar with PSSE and $65.8 \%$ were comfortable prescribing PSSE postoperatively. The largest group of respondents had been in practice for more than 21 years, suggesting that older physicians were more likely to recommend PT. Of the respondents, $28 \%$ agreed that $>12$ weeks postoperation was the ideal time for PSSE referral, followed by 6 to 8 weeks postoperation $(26.2 \%)$ and immediately postoperation (18\%). North American spine surgeons and those trained in pediatric and orthopedic fellowships were more familiar with PSSE $(P<.05)$. These results are summarized in Table 3. Despite being more familiar with PSSE, there was no difference in the rate of referral to PSSE among pediatric, orthopedic, or orthoneuro combined fellowship training. The characteristics of surgeons using PSSE are summarized in Tables 4 and 5.

\section{DISCUSSION}

Physiotherapeutic scoliosis-specific exercise is emerging as a viable nonoperative treatment for the AIS population ${ }^{4,10,11,17}$ but has been relatively understudied in adult idiopathic scoliosis and de novo degenerative scoliosis. ${ }^{5}$

In North America, the Scoliosis Research Society, Pediatric Orthopaedic Society of North America, and American Association of Orthopaedic Surgeons believe scoliosis-specific exercises can decrease the likelihood of curve progression in adolescents. ${ }^{18}$ There is no similar collective guidance on adults with scoliosis. In addition, there is insufficient evidence to support the efficacy of nonsurgical modalities of treatment for adults with scoliosis. Evidence to date suggests that operative intervention is superior to nonoperative intervention, with improved quality-of-life measures following operative management. ${ }^{19-21}$ However, surgical management should be reserved for clinical presentations dominated by pain, neurological involvement, decreased function, and when nonoperative management has failed. ${ }^{1}$ Nonoperative intervention 
Table 3. Surgeon use of PT and PSSE.

\begin{tabular}{|c|c|c|}
\hline & Response & n $(\%)$ \\
\hline \multirow{5}{*}{$\begin{array}{l}\text { If you indicated that you refer patients to physical therapy } \\
\text { after scoliosis fusion surgery, what percentage of your } \\
\text { patients do you refer? }\end{array}$} & $0 \%-20 \%$ & $26(40)$ \\
\hline & $21 \%-40 \%$ & $5(7.7)$ \\
\hline & $41 \%-60 \%$ & $6(9.2)$ \\
\hline & $61 \%-80 \%$ & $7(10.8)$ \\
\hline & $81 \%-100 \%$ & $21(32.3)$ \\
\hline \multirow{3}{*}{$\begin{array}{l}\text { If you refer patients for physical therapy, what are the } \\
\text { reasons for referral? }\end{array}$} & Persistent pain & $27(40.30)$ \\
\hline & Impaired balance and gait & $23(34.30)$ \\
\hline & Difficulty with ADLs & $17(25.40)$ \\
\hline \multirow[t]{3}{*}{$\begin{array}{l}\text { If you do not refer patients after scoliosis fusion surgery to } \\
\text { physical therapy, what are the reasons you do not refer? }\end{array}$} & $\begin{array}{l}\text { Lack of evidence for the role of } \\
\text { physical therapy }\end{array}$ & $15(31.25)$ \\
\hline & $\begin{array}{l}\text { Lack of perceived value for the role } \\
\text { of physical therapy }\end{array}$ & $24(50.00)$ \\
\hline & $\begin{array}{l}\text { Lack of access to physical therapists } \\
\text { with appropriate knowledge of } \\
\text { scoliosis and surgical procedure/ } \\
\text { precautions }\end{array}$ & $9(18.75)$ \\
\hline \multirow[t]{4}{*}{ What time frame after surgery is ideal to refer to PSSE? } & Immediately post-op & $11(18.3)$ \\
\hline & 3-4 weeks post-op & $7(11.67)$ \\
\hline & $6-8$ weeks post-op & $16(26.67)$ \\
\hline & $8-12$ weeks post-op & $9(15)$ \\
\hline
\end{tabular}

Abbreviations: ADLs, activities of daily living; post-op, postoperative; PSSE, physiotherapeutic scoliosis-specific exercise; PT, physical therapy.

should be the first line of defense for ASD, and emerging nonoperative treatment techniques such as PSSE deserve a thorough evaluation. This study reports on survey results from 98 surgeons on their attitudes toward physical therapy and, in particular, PSSE as a distinct treatment option in older patients with ASD.

Study results demonstrated that a significant number of surgeons $(36.36 \%)$ did not use PT at all for patients with ASD. This result may reflect the current evidence base that demonstrates the increased efficacy of operative management over nonoperative management in this patient population. ${ }^{19-21}$

For surgeons referring patients to PT, a majority referred patients with deformity for nonoperative

Table 4. Familiarity and knowledge of PSSE among surveyed surgeons.

\begin{tabular}{lrrr}
\hline & No & Yes & P Value \\
\hline Region & & & .001 \\
North America & 9 & 54 & \\
Europe & 2 & 8 & \\
Asia & 6 & 2 & \\
South America & 7 & 0 & \\
Australia & 0 & 1 & .696 \\
Middle East & 0 & 1 & \\
Years in training & & & \\
0-10 & 7 & 17 & .019 \\
11-20 & 5 & 20 & \\
21 or more & 12 & 30 & \\
Specialty & & & \\
Orthopedic spine surgeon & 22 & 65 & .002 \\
Neurosurgical spine surgeon & 2 & 0 & .001 \\
Fellowship & & & .781 \\
Pediatric & 6 & 41 & \\
Orthopedic spine & 22 & 28 & \\
Ortho-neuro combined & 1 & 2 & \\
\hline
\end{tabular}

management $(91.07 \%)$, with relatively fewer surgeons referring patients after surgery $(71.43 \%)$. Furthermore, a majority of surgeons referring patients to PT or PSSE referred patients for persistent pain or impaired balance and gait, rather than for difficulty with activities of daily living or impaired respiratory function, which suggests a perceived benefit of PT for specific symptoms of ASD.

Survey results showed that approximately $71 \%$ of respondents referred patients for PT after scoliosis fusion surgery; however, only approximately $66 \%$ felt comfortable referring to a therapist who provides PSSE following fusion surgery. These results indicate either lack of access to therapists trained in PSSE or remaining skepticism regarding

Table 5. Surgeons comfortable recommending PSSE.

\begin{tabular}{lrrr}
\hline & No & Yes & P Value \\
\hline Region & & & .165 \\
North America & 19 & 38 & \\
Europe & 5 & 3 & \\
Asia & 0 & 5 & \\
South America & 1 & 2 & \\
Australia & 1 & 0 & .830 \\
Middle East & 0 & 1 & \\
Years in training & & & \\
0-10 & 6 & 12 & \\
11-20 & 9 & 14 & \\
21 or more & 11 & 24 & \\
Specialty & & & \\
Orthopedic spine surgeon & 26 & 48 & .109 \\
Neurosurgical spine surgeon & 0 & 0 & .633 \\
Fellowship & & & \\
Pediatric & 18 & 25 & \\
Orthopedic spine & 11 & 27 & \\
Ortho-neuro combined & 1 & 1 & \\
\hline
\end{tabular}


the benefit of PT and PSSE in the postoperative process in ASD management. In addition, there was just a $5 \%$ difference in referrals for traditional PT following surgery $(71.43 \%)$ and comfort level in referring to a therapist trained in PSSE postoperatively $(65.79 \%)$, suggesting a similar perspective for the role of PSSE as for traditional PT in postoperative management.

Although a majority of surgeons reported feeling comfortable referring patients to PSSE for scoliosis after fusion surgery, there appears to be a lack of consensus over the optimal period for referral, as indicated by the stratified responses. This illustrates some confusion regarding the uses of PT and PSSE and implications of the therapy for postoperative symptom management. Respondents who did not prescribe PT postoperatively reported skepticism due to lack of perceived value from PT. The lack of consensus as well as lack of perceived value may stem from the lack of evidence around rehabilitation after spine deformity surgery. ${ }^{22}$

There are various limitations to this particular study, primarily that only 98 surgeons participated in the survey; this was a significantly smaller sample size than expected given the number of participants eligible for this study. This introduces the possibility of selection bias, because respondents with an interest in nonoperative interventions may have been more likely to respond to the survey. Fortyeight percent of respondents were surgeons who had been in practice for more than 21 years. This is significant because conservative treatment options such as PSSE and other exercise treatment methods might not have been part of medical training or even in existence in earlier years. However, these data might also indicate the possibility that older surgeons are more likely to recommend PT or PSSE, given the percentage of surgeons indicating their use of PT as a treatment option nonoperatively and postoperatively.

With the prevalence of ASD reaching as high as $68 \%,{ }^{2}$ valuable and effective treatment options need to be sought out and studied. Operative treatment methods can be expensive and burdensome on patients, whereas nonoperative methods are not always successful in treating patients with significant deformity. Although patients are becoming more familiar with PSSE and other nonsurgical treatment options for ASD, the results show that surgeons are familiar and comfortable with prescribing PSSE, but don't despite patient familiarity. North Amer- ican spine surgeons and those trained in pediatric or orthopedic fellowships are more familiar with PSSE but do not recommend it at a higher rate. Those surgeons report significant skepticism regarding the perceived benefit of PT or PSSE despite growing literature such as the BrAIST study supporting the possibility of nonoperative treatments for AIS and future large-scale observational studies. Surgeons who do prescribe PSSE for scoliosis treatment after fusion surgery have a lack of consensus on the optimal time frame for PT or PSSE treatment, adding to the need for a more comprehensive study on the effectiveness of PT or PSSE in the treatment of ASD.

\section{CONCLUSIONS}

The results show that the majority of respondents prescribed PT solely for nonoperative treatment. Respondents who did not prescribe PT postoperatively reported skepticism due to a lack of perceived value from PT. There is also considerable skepticism regarding the benefit of PSSE for postoperative symptom management in ASD, with two-thirds of the respondents familiar with PSSE and comfortable in prescribing PSSE postoperatively. The data show that despite being familiar or comfortable with prescribing PSSE, PT is not routinely used. Furthermore, North American spine surgeons and those trained in pediatric and orthopedic fellowships were more familiar with PSSE, there was no difference in the rate of referral. Therefore, further research regarding the use of PT and PSSE as an effective treatment option for the perioperative and nonoperative management of ASD is necessary to elucidate the benefits of this intervention.

\section{REFERENCES}

1. Aebi M. The adult scoliosis. Eur Spine J. 2005;14(10):925948. https://doi.org/10.1007/s00586-005-1053-9

2. Ames CP, Scheer JK, Lafage V, et al. Adult spinal deformity: epidemiology, health impact, evaluation, and management. Spine Deform. 2016;4(4):310-322. https://doi. org/10.1016/j.jspd.2015.12.009

3. Weinstein SL, Dolan LA, Wright JG, Dobbs MB. Effects of bracing in adolescents with idiopathic scoliosis. $N$ Engl $J$ Med. 2013;369(16):1512-1521. https://doi.org/10.1056/NEJ Moa 1307337

4. Schreiber S, Parent EC, Moez EK, et al. Schroth physiotherapeutic scoliosis-specific exercises added to the standard of care lead to better Cobb angle outcomes in adolescents with idiopathic scoliosis - an assessor and statistician blinded randomized controlled trial. PLoS One. 2016;11(12). https://doi.org/10.1371/journal.pone.0168746 
5. Monticone M, Ambrosini E, Cazzaniga D, et al. Adults with idiopathic scoliosis improve disability after motor and cognitive rehabilitation: results of a randomised controlled trial. Eur Spine J. 2016;25(10):3120-3129. https://doi.org/10.1007/ s00586-016-4528-y

6. Fusco C, Zaina F, Atanasio S, Romano M, Negrini A, Negrini S. Physical exercises in the treatment of adolescent idiopathic scoliosis: an updated systematic review. Physiother Theory Pract. 2011;27(1):80-114.https://doi.org/10.3109/09593985. 2010.533342

7. Berdishevsky H, Lebel VA, Bettany-Saltikov J, et al. Physiotherapy scoliosis-specific exercises - a comprehensive review of seven major schools. Scoliosis Spinal Disord. 2016;11(1):20. https://doi.org/10.1186/s13013-016-0076-9

8. "The Schroth method for physical therapists for scoliosis treatment." 2016. Schroth Barcelona Institute, 2016 website, http://www.schroth-barcelonainstitute.com/.

9. Schwab FJ, Dubey A, Gamez L, et al. Adult scoliosis: prevalence, SF-36, and nutritional parameters in an elderly volunteer population. Spine (Phila Pa 1976). 2005;30(9):10821085. https://doi.org/10.1097/01.brs.0000160842.43482.cd

10. Kuru T, Yeldan I, Dereli EE, Özdinçler AR, Dikici F, Çolak I. The efficacy of three-dimensional Schroth exercises in adolescent idiopathic scoliosis: a randomised controlled clinical trial. Clin Rehabil. 2016;30(2):181-190. https://doi.org/10.1177/ 0269215515575745

11. Monticone M, Ambrosini E, Cazzaniga D, Rocca B, Ferrante S. Active self-correction and task-oriented exercises reduce spinal deformity and improve quality of life in subjects with mild adolescent idiopathic scoliosis. Results of a randomised controlled trial. Eur Spine J. 2014;23(6):1204-1214. https://doi.org/10.1007/s00586-014-3241-y

12. Mordecai SC, Dabke H V. Efficacy of exercise therapy for the treatment of adolescent idiopathic scoliosis: a review of the literature. Eur Spine J. 2012;21(3):382-389. https://doi.org/ 10.1007/s00586-011-2063-4

13. Negrini A, Negrini MG, Donzelli S, Romano M, Zaina F, Negrini S. Scoliosis-specific exercises can reduce the progression of severe curves in adult idiopathic scoliosis: a long-term cohort study. Scoliosis. 2015;10(1):1-7. https://doi. org/10.1186/s13013-015-0044-9

14. Romano M, Minozzi S, Zaina F, et al. Exercises for adolescent idiopathic scoliosis: a Cochrane systematic review. Spine (Phila Pa 1976). 2013;38(14):E883-E893. https://doi.org/ 10.1097/BRS.0b013e31829459f8

15. Weiss H-R, Negrini S, Hawes MC, et al. Physical exercises in the treatment of idiopathic scoliosis at risk of brace treatment-SOSORT consensus paper 2005. Scoliosis. 2006;1(1):6. https://doi.org/10.1186/1748-7161-1-6

16. Kwan KYH, Cheng ACS, Koh HY, Chiu AYY, Cheung KMC. Effectiveness of Schroth exercises during bracing in adolescent idiopathic scoliosis: results from a preliminary
study-SOSORT Award 2017 winner. Scoliosis Spinal Disord. 2017;12(1):32. https://doi.org/10.1186/s13013-017-0139-6

17. Schreiber S, Parent EC, Hedden DM, Moreau M, Hill D, Lou E. Effect of Schroth exercises on curve characteristics and clinical outcomes in adolescent idiopathic scoliosis: protocol for a multicentre randomised controlled trial. $J$ Physiother. 2014;60(4):234. https://doi.org/10.1016/j.jphys.2014.08.005

18. Hresko MT, Talwalkar VR SR. Screening for the early detection for idiopathic scoliosis in adolescents: SRS/POSNA/ AAOS/AAP position statement. Scoliosis Research Society website. https://www.srs.org

19. Liu S, Schwab F, Smith JS, et al. Likelihood of reaching minimal clinically important difference in adult spinal deformity: a comparison of operative and nonoperative treatment. Ochsner J. 2014;14(1):67-77. http://www.pubmedcentral.nih.gov/ articlerender.fcgi?artid $=3963055 \&$ tool $=$ pmcentrez\&rendertype $=$ abstract. Accessed December 3, 2019.

20. Smith JS, Lafage V, Shaffrey CI, et al. Outcomes of operative and nonoperative treatment for adult spinal deformity: a prospective, multicenter, propensity-matched cohort assessment with minimum 2-year follow-up. Neurosurgery. 2016;78(6):851861. https://doi.org/10.1227/NEU.0000000000001116

21. Everett CR, Patel RK. A systematic literature review of nonsurgical treatment in adult scoliosis. Spine (Phila $\mathrm{Pa}$ 1976). 2007;32(suppl 19):S130-S134. https://doi.org/10.1097/ BRS.0b013e318134ea88

22. Wainwright TW, Immins T, Middleton RG. Enhanced recovery after surgery (ERAS) and its applicability for major spine surgery. Best Pract Res Clin Anaesthesiol. 2016;30(1):91102. https://doi.org/10.1016/j.bpa.2015.11.001

Disclosures and COI: The authors received no financial support for the research, authorship, and/ or publication of this article and report no conflicts of interest.

Corresponding Author: Charla R. Fischer, MD, NYU Langone Orthopedic Hospital, 246 East 20th Street, New York, NY 10003. Phone: (646) 356-9415; Fax: (646) 356-9413; Email: charla. fischer@nyumc.org.

Published 31 December 2019

This manuscript is generously published free of charge by ISASS, the International Society for the Advancement of Spine Surgery. Copyright $\odot 2019$ ISASS. To see more or order reprints or permissions, see http://ijssurgery.com. 